\author{
UNIVERSIDADE DE SÃO PAULO \\ FACULDADE DE ODONTOLOGIA DE BAURU
}

PATRICK HENRY MACHADO ALVES

Avaliação da remodelação óssea marginal peri-implantar e correlação com a espessura gengival mensurada por tomografia computadorizada em implantes submetidos a carga imediata 

PATRICK HENRY MACHADO ALVES

\section{Avaliação da remodelação óssea marginal peri-implantar e correlação com a espessura gengival mensurada por tomografia computadorizada em implantes submetidos a carga imediata}

\footnotetext{
Tese apresentada a Faculdade de Odontologia de Bauru da Universidade de São Paulo para obtenção do título de Doutor em Ciências no Programa de Ciências Odontológicas Aplicadas, na área de concentração Reabilitação Oral.

Orientador: Profa. Dra. Ana Lucia Pompeia Fraga de Almeida
} 
Alves, Patrick Henry Machado

Avaliação da remodelação óssea marginal peri-implantar e correlação com a espessura gengival mensurada por tomografia computadorizada em implantes submetidos a carga imediata / Patrick Henry Machado Alves. -- Bauru, 2020. 57 p. : il. ; $31 \mathrm{~cm}$.

Tese (doutorado) -- Faculdade de Odontologia de Bauru, Universidade de São Paulo, 2020.

Orientadora: Prof. ${ }^{a}$ Dr. ${ }^{a}$ Ana Lucia Pompeia Fraga de Almeida

Autorizo, exclusivamente para fins acadêmicos e científicos, a reprodução total ou parcial desta tese, por processos fotocopiadores e outros meios eletrônicos.

Assinatura:

Data:

Comitê de Ética da FOB-USP

CAAE: 50811015.0.0000.5417

Data: $24 / 11 / 2015$ 
FOLHA DE APROVAÇÃO 



\section{DEDICATÓRIA}

Dedico este estudo aos meus filhos Maitê e Mateus.

$\mathrm{O}$ amor por vocês dá sentido à minha vida. 



\section{AGRADECIMENTOS}

À Deus, pela minha vida e por me permitir lutar por meus objetivos.

João Carlos e Tânia Luzia agradeço pelo amor e por acreditarem comigo em meus sonhos lado a lado. Amo vocês para sempre.

À Thereza, pelo amor, cuidado e carinho que dedica a mim e nosso filhos. Amo você.

Aos meus irmãos Frederick e Tacianne. Por caminharem comigo desde o início.

Ao Prof. Dr. Luiz Fernando Pegoraro. Não é à toa que é uma referência para a odontologia. Minha eterna admiração pela sua dedicação na carreira docente odontológica. Seu bom senso e senso crítico foram fundamentais para minha formação.

Aos professores do Departamento de Prótese pelos ensinamentos e todo aprendizado possibilitado. É uma honra poder absorver um pouco do conhecimento passado por todos vocês.

Ao Prof. Dr. José Roberto Pereira Lauris por dispensar seu tempo para realizar as estatísticas deste trabalho.

Todos os funcionários do Departamento de Prótese, em especial à Deborah, Cleide e Hebe.

Agradeço imensamente à Camila, Everardo e Ernesto. Trabalhar com vocês foi uma oportunidade ímpar. Tenho enorme gratidão pelo convívio que tivemos.

A todos os colegas de curso de Doutorado (Andréa Falcão, Fernanda Piras,, Gustavo Andrade, Ilana Ramalho, Oscar Marcillo, Thereza Pacheco, Verena Cunha e Vinícius Rizzo) pelo excelente convívio, conhecimentos compartilhados e amizade. Vocês facilitaram essa jornada.

Aos demais alunos de pós-graduação da Reabilitação Oral.

Agradeço todos os pacientes que participaram deste estudo. Sou grato pela confiança em nosso trabalho. 

À SIN sistema de implantes, pela doação de todos os implantes e componentes protéticos utilizados no estudo. Muito obrigada!

À Faculdade de Odontologia de Bauru FOB-USP, pela oportunidade concedida. Meus 14 anos aqui me fazem ser o profissional que sou hoje.

A Coordenação de Aperfeiçoamento de Pessoal de Nível Superior (CAPES) pela concessão da bolsa de estudo.

A todos que colaboraram direta ou indiretamente desde trabalho e ao longo de minha vida. 



\section{AGRADECIMENTO ESPECIAL}

À Profa ${ }^{\text {Dra }}$ Ana Lucia Pompeia Fraga de Almeida, por ter sido a principal responsável pelo meu início na carreira acadêmica. Admiro muito você como Profa $\mathrm{e}$ principalmente como Ser Humano. Por ter me orientado neste estudo, agradeço imensamente.

Ao Prof. Dr. Estevam Augusto Bonfante por me dar a oportunidade de participar desta equipe de pesquisa e principalmente deste estudo. Te admiro muito. 

"Mãos que atuam e fazem o bem, mãos que trabalham e não se detêm, mãos amorosas que os fracos amparam, mãos que rezam e sempre rezaram, mãos que se elevam num gesto profundo, é dessas mãos que precisa o mundo." 



\section{RESUMO}

O objetivo deste estudo clínico foi avaliar a remodelação óssea peri-implantar em implantes com conexão cônica interna submetidos a carga imediata com coroas em contato oclusal em máxima intercuspidação em região posterior e unitários e a correlação desta remodelação com a espessura dos tecidos gengivais. Vinte e nove pacientes com perdas dentárias unitárias posteriores foram selecionados para receber implantes de conexão cônica interna com carga imediata e contados oclusais em máxima intercuspidação e coroas finais. Todos os pacientes tiveram a espessura gengival medida durante o planejamento através de uma tomografia computadorizada de feixe cônico com afastamento dos lábios e bochechas. Os pacientes foram divididos em dois grupos, e o Grupo 1 recebeu coroas metalocerâmicas e o Grupo 2 recebeu coroas de uma cerâmica híbrida. Todos os implantes tiveram um torque de instalação mínimo de $32 \mathrm{~N} / \mathrm{cm}$ durante a cirurgia e receberam as coroas finais 4 dias após o procedimento cirúrgico. Foi avaliada a remodelação óssea peri-implantar em 9 dias (T1), 6 meses (T2) e 1 ano (T3) através de radiografias periapicais padronizadas. A média da espessura gengival e da remodelação óssea marginal peri-implantar para o Grupo 1 foi de $1,74 \mathrm{~mm}$ e 1,31 mm respectivamente enquanto para o Grupo 2 as médias foram de $2,23 \mathrm{~mm}$ e $0,68 \mathrm{~mm}$. O coeficiente de correlação de Pearson mostrou uma correlação moderada entre a remodelação óssea peri-implantar e a espessura gengival para o Grupo $1(r=-495)$ e uma correlação forte para o Grupo $2(r=-681)$. Dentro das limitações do estudo os resultados sugerem que a utilização de carga imediata e implantes de conexão cônica interna não foram capazes de evitar a remodelação óssea marginal peri-implantar e a espessura gengival parece ser um importante fator neste processo.

Palavras-chave: Implantes dentais. Perda óssea. Gengiva 



\section{ABSTRACT \\ Evaluation of marginal peri-implant bone remodeling and correlation with gingival thickness measured by computed tomography in implants with immediate loading}

The objectives of this clinical study were to evaluate the peri-implant bone's remodeling in implants with internal conical connection under immediate loading, with crowns in occlusal contact at maximum intercuspation in the posterior region and units, and to evaluate the correlation of the bone's remodeling with the gingival tissues thickness. Twenty-nine patients with posterior unitary dental absence were selected to receive implants with internal conical connection under immediate loading and occlusal counting at maximum intercuspation and final crowns. All patients' gingival thickness were measured during planning using computed cone beam tomography, with separation of the lips and cheeks. Patients were divided into two groups: Group 1 received metal-ceramic crowns, and Group 2 received hybrid ceramic crowns. All implants had a minimum installation torque of $32 \mathrm{~N} / \mathrm{cm}$ and received final crowns 4 days after the surgical procedure. The peri-implant bone remodeling in 9 days (T1), 6 months (T2) and 1 year (T3) were assessed using standardized periapical radiographs. The average gingival thickness and marginal peri-implant bone remodeling for Group 1 was $1.74 \mathrm{~mm}$ and $1.31 \mathrm{~mm}$, respectively, while for Group 2 the averages were 2.23 $\mathrm{mm}$ and $0.68 \mathrm{~mm}$. While pearson's correlation coefficient showed a moderate correlation between peri-implant bone remodeling and gingival thickness for Group 1 $(r=-495)$, it showed a strong correlation for Group $2(r=-681)$. Under the scope of this study, the results suggested that the use of conical connection implants under immediate loading were not able to prevent peri-implant marginal bone remodeling, and gingival thickness seems to be an important factor in this process.

Key words: Dental implants. Crestal bone loss. Gingiva. 



\section{LISTA DE FIGURAS}

Figura 1 - Método de avaliação tomográfica do biótipo gengival..........................28

Figura 2 - Radiografias medindo o nível ósseo mesial em T1, T2 e T3................30 



\section{LISTA DE TABELAS}

Tabela 1 - Média e desvio padrão do nível ósseo e espessura gengival para o Grupo 1

Tabela 2 - Média e desvio padrão do nível ósseo e espessura gengival para o Grupo 2

Tabela 3 - Comparação do nível ósseo nos 3 tempos (ANOVA a um critério para medidas repetidas e Teste de Tukey) para o Grupo 1

Tabela 4 - Comparação do nível ósseo nos 3 tempos (ANOVA a um critério para medidas repetidas e Teste de Tukey) para o Grupo 2

Tabela 5 - Média e desvio padrão da remodelação óssea para o grupo 1.

Tabela 6 - Média e desvio padrão da remodelação óssea para o Grupo 2 ........ 37

Tabela 7 - Comparação do nível ósseo e quantidade de remodelação em ambos os grupos

Tabela 8 - Correlação entre remodelação óssea e espessura gengival para o Grupo 1

Tabela 9 - Correlação entre remodelação óssea e espessura gengival para o grupo 2 



\section{SUMÁRIO}

1 INTRODUÇÃO E REVISÃO DE LITERATURA 13

2 PROPOSIÇÃO. 23

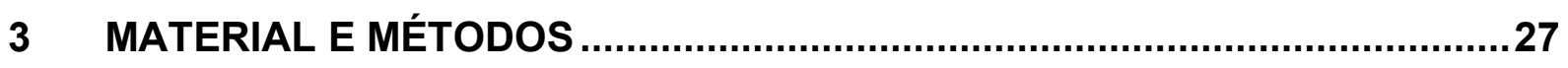

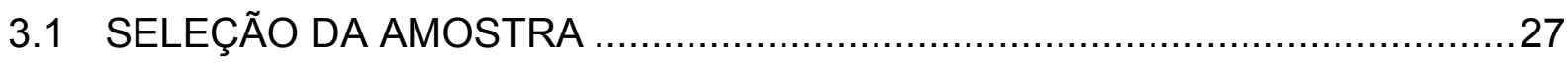

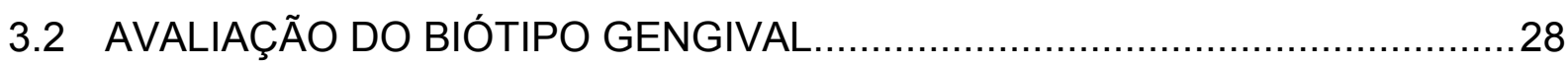

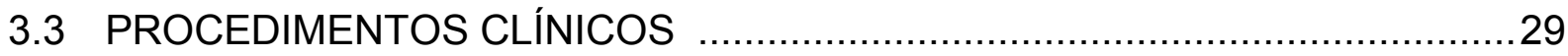

3.4 AVALIAÇÃO DA REMODELAÇÃO ÓSSEA MARGINAL PERI-IMPLANTAR ...30

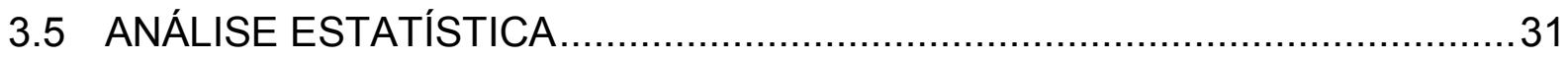

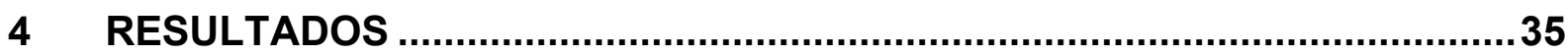

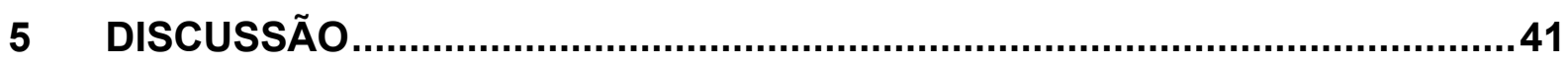

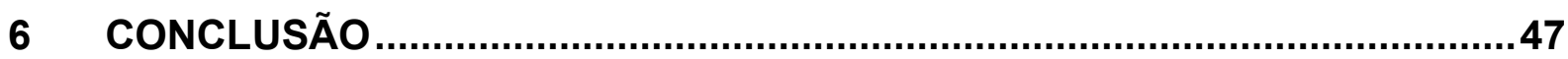

REFERÊNCIAS ................................................................................ 51 

1 INTRODUÇÃo E REVISÃO DE LITERATURA 



\section{INTRODUÇÃO E REVISÃO DE LITERATURA}

As distâncias biológicas periodontais, espaço compreendido entre o nível da crista óssea alveolar até a margem gengival, funciona como a junção entre os tecidos moles periodontais e o dente e tem como principal objetivo prover a separação do ambiente interno e externo da cavidade oral. Estudo clássico descreveu a dimensão desta distância como uma média de 2,73mm (GARGIULO et al., 1961). A partir deste estudo, muitos profissionais utilizaram a medida de $3 \mathrm{~mm}$ como parâmetro clínico, no planejamento periodontal. Vale ressaltar que este estudo, além de utilizar uma medida média, foi realizado em cadáveres, podendo haver alterações dimensionais destes espécimes (contração "post morten"), sendo possível assim haver diferenças nestas medidas.

Estudos mostraram haver variações destas medidas, nos diferentes grupos de dentes e entre diferentes pacientes (MENDONÇA, 2001 e COESTA, 2003), evidenciando que alguns pacientes necessitam de um maior ou menor espaço para formação do sulco gengiva, epitélio juncional e inserção conjuntiva. Mendonça (2001) em seu estudo encontrou medida média de $2,5 \mathrm{~mm}$ com intervalos de valores de 1,06 a $6,5 \mathrm{~mm}$. Para Coesta (2003), a média encontrada foi de $4,14 \mathrm{~mm}$. Isso posto, fica claro que o que pode comprometer a homeostasia do periodonto, através da invasão do espaço biológico em um paciente, pode ser completamente bem tolerado por outros, tendo em vista estas variações de medidas.

O efeito da violação deste espaço por uma cárie, restauração, coroa ou fratura, é a inflamação tecidual (WAERHAUG, 1960) seguida pela migração apical das distâncias biológicas afim de manter o contato entre a inserção conjuntiva e epitélio juncional com um tecido dentário saudável. Esta migração ocorre às custas da liberação do fator de crescimento epitelial (EFG) e consequente remodelação do tecido ósseo (PARMA-BENFENATI et al., 1985, PARMA-BENFENATI et al., 1986; TAL et al., 1989).

Áreas desdentadas, apresentam apenas uma camada de tecido conjuntivo recoberta por tecido epitelial, não apresentando sulco gengival nem epitélio juncional. Quando instalamos um implante dentário e uma coroa sobre o mesmo, há a 
necessidade de reformulação dos tecidos moles, para formação de uma nova estrutura chamada de espaço biológico peri-implantar, que se assemelha ao tecido mole ao redor dos dentes (COCHRAN, et al., 1997). Apesar de não haver uma inserção do tecido conectivo, o mesmo se forma ao redor do implante, chamando-se adesão conectiva, estando o epitélio juncional e o sulco, organizados de maneira muito semelhantes ao tecido periodontal. A medida média dos tecidos periimplantares é de 3,65 mm (BERGLUNDH; LINDHE, 1996).

Para se obter espaço para formação destas três estruturas ao redor dos implantes, muitas vezes o tecido ósseo peri-implantar também sofre a ação do EGF, migrando para apical e permitindo a acomodação do tecido mole. Este fenômeno fisiológico é descrito na literatura como saucerização e no passado considerava-se normal uma perda de $1.5 \mathrm{~mm}$ no primeiro ano em função e $0.2 \mathrm{~mm}$ nos anos subsequentes (ALBREKTSSON, et al., 1986). Com o passar dos anos, novos parâmetros de sucesso dos tecidos ao redor dos implantes foram desenvolvidos e estudos mais atuais mostram remodelação óssea marginal média inferiores, na ordem de aproximadamente 0.5mm (LAURELL; LUNDGREN, 2011; CASSETTA, et al., 2016; GUVEN, et al., 2020). Esta pequena remodelação óssea, ocorrida no primeiro ano do implante em função pode ser considerada fisiológica para acomodação dos tecidos moles peri-implantares, não sendo classificada como um processo patológico periimplantar, porém não deve ser progressiva nos anos subsequentes (COLI et al., 2017). Sendo assim é importante diferenciar este processo fisiológico de uma peri-implantite, um processo inflamatório e infeccioso que resulta na perda óssea e de inserção ao redor dos implantes (PETKOVIC et al., 2010).

Muitos autores vêm estudando este processo de remodelação óssea fisiológica peri-implantar ao longo dos anos e várias são as teorias para que este processo ocorra, entre elas: técnica cirúrgica adotada, descolamento do periósteo durante a instalação do implante, tipo de conexão utilizada, tipo de retenção protética (cimentada ou parafusada), material restaurador utilizado, altura da cinta/transmucoso do intermediário, momento da carga (cirurgia em 2 estágios, 1 estágio ou carga imediata), design do implante, presença de um microgap na interface entre o implante e o intermediário ocasionando micro movimentação, presença de microrganismos e infiltrado inflamatório e o posicionamento do implante, principalmente no sentido 
ápico-coranal (CANEVA et al., 2010; DIAS et al., 2012; BROGGINI et al., 2003; SHIN et al., 2006).

Dentre as medidas comumente utilizadas para minimizar ou evitar esta remodelação, está o conceito de platform switching, onde um componente protético mais estreito que a plataforma do implante é utilizado para permitir a acomodação do epitélio juncional sobre a mesma favorecendo assim a formação das distâncias biológicas no sentido horizontal minimizando a remodelação óssea marginal e migração do periodonto para apical para manutenção do homeostasia dos tecidos (LAZZARA; PORTER, 2006).

Os autores de uma revisão sistemática de estudos clínicos em humanos tem sugerido ainda, que o fato de se instalar um intermediário protético no ato cirúrgico da instalação do implante (one-abutment at one-time), evitando assim e desconexão e reconexão de componentes protéticos, ao nível do epitélio juncional, possam minimizar esta remodelação (PERROTTI et al., 2019). Apesar dos resultados, os autores ressaltam que o significado clínico destas alterações do nível ósseo ainda carece de mais estudos.

Considerando que a preservação óssea é fundamental para manutenção e estética dos tecidos peri-implantares, muitos estudos foram realizados sobre 0 conceito de platform switching e um marketing massivo das industrias foi realizado tentando evidenciar a superioridade de alguns tipos de plataforma sobre outras (ESPOSITO et al., 2016), principalmente sobre as conexões cônicas internas, erroneamente chamadas de cone morse, por estas sempre apresentarem intercâmbio de plataforma. Seguindo os conceitos da Associação Brasileira de Normas Técnicas (ABNT), para uma conexão ser chamada de morse, é necessário que a conexão não seja por parafuso, possua um ângulo de divergência de no máximo 3,01º no mínimo 9,04 mm de diâmetro da embocadura, o que não ocorre em nenhum modelo de implante disponível no mercado (TUNES et al., 2015). Alguns estudos já vêm demonstrando não haver um total selamento bacteriano nestes tipos de conexão (RACK et al., 2010; RICOMINI FILHO et al., 2010; SCHMITT et al., 2013).

Embora algumas revisões sistemáticas mostrem que a perda óssea periimplantar seja ligeiramente menor quando utilizamos implantes com platform switching, sejam eles hexagonais externos, internos ou ainda cônicos internos, 
(ATIEH et al., 2010; AL-NSOUR et al, 2012; HEREKAR et al, 2014; STRIETZEL et al, 2015; SANTIAGO Jr et al, 2015; MEDEIROS et al., 2016; CARICASULO et al., 2017;), estes resultados devem ser interpretados com cautela, devido a heterogeneidade da amostra e ao período de tempo de acompanhamento reduzidos de muitos estudos, a posição ápico coronal deste implantes, a presença ou não de uma superfície texturizada e os métodos de avaliação do nível ósseo utilizados. Outro ponto importante a ser considerado é que apesar destes estudos mostrarem uma melhor preservação óssea ao redor destes implantes, os artigos relatam bom desempenho clínico em outros tipos de conexão (ATIEH et al., 2010; VIGOLO et al., 2016).

Por outro lado, vários estudos, não demonstram diferenças estatisticamente significantes na remodelação óssea marginal peri-implantar em implantes com ou sem platform switching (ENKLING et al., 2013; LIN et al., 2013; ESPOSITO et al., 2016; MELONI et al., 2016) nem entre implantes com conexões diferentes (LIN et al., 2013; ESPOSITO et al., 2016). Crespi et al, encontram resultados semelhantes de remodelação óssea peri-implantar em implantes do tipo hexágono externo e cônico interno, mesmo quando submetidos a carga imediata (CRESPI el al., 2009).

Grande parte dos trabalhos, tentam evidenciar que um determinado tipo de implante pode preservar melhor os tecidos peri-implantares minimizando assim a saucerização por meio de uma melhor estabilidade mecânica ou um melhor selamento bacteriano, entretanto poucos estudos realizados levaram em consideração o fator biológico da espessura dos tecidos moles, presentes ao redor dos implantes. Neste contexto, uma revisão de literatura verificou que apesar de haver muitos trabalhos sobre o espaço biológico peri-implantar, sua dimensão e influência na remodelação óssea, um número reduzido destes trabalhos são clínicos em humanos havendo muitos trabalhos em modelos animais que evidenciam a influência da espessura gengival neste processo de remodelação óssea (LINKEVICIUS; APSE, 2008)

Havendo essa lacuna na literatura, uma série de trabalhos foram realizados para verificar a influência da espessura gengival neste processo de remodelação óssea peri-implantar. Um estudo realizado com implantes tissue level, instalados 2 $\mathrm{mm}$ acima da crista óssea, divididos em 2 grupos pela espessura gengival medida in loco com uma sonda periodontal durante o procedimento cirúrgico evidenciou uma maior remodelação óssea marginal em implantes com a espessura gengival menor que $2 \mathrm{~mm}$ quando comparada ao grupo com gengiva mais espessa que $2 \mathrm{~mm}$. No 
grupo com gengiva fina uma remodelação óssea da ordem de 1,45 mm pode ocorrer, a despeito da instalação supra crestal do implante, ou seja afastando o gap do osso (LINKEVICIUS et al., 2009). Um estudo piloto realizado pelos mesmos autores, em pacientes com espessura gengival fina (menor que $2 \mathrm{~mm}$ ), acompanhou implantes com e sem platform switching por 1 ano. Ambos os tipos de implantes apresentaram remodelação óssea marginal semelhantes, sem diferenças estatisticamente significantes (LINKEVICIUS et al., 2010).

Cento e três pacientes de um estudo receberam implantes do tipo hexágono externo de 4,6 mm de diâmetro. Os pacientes foram separados em 3 grupos: grupo A (biótipo fino), grupo B (biótipo fino, mas que receberam enxerto com uma membrana alógena) e grupo C (biótipo espesso). Os resultados apresentados após o acompanhamento destes pacientes demonstraram que os implantes do grupo A tiveram uma remodelação óssea mais acentuada quando comparados com o grupo B e C. Vale ressaltar que mesmo se tratando de um implante com uma conexão pouco estável, a média de remodelação óssea (de 0,25 a $0,36 \mathrm{~mm}$ ) foi pequena quando o biótipo é espesso (LINKEVICIUS et al., 2013). Estudo semelhante foi realizado, porém utilizando implantes com platform switching. Nos implantes onde a gengiva era espessa ou a mesma foi aumentada por enxerto alógeno, a remodelação era significantemente menor quando comparada ao grupo com biótipo fino, resultado semelhante ao encontrado nos implantes hexagonais (PUISYS; LINKEVICIUS, 2015).

Em 2015, um estudo foi realizado para avaliar a influência do biótipo gengival no processo de saucerização. Foram avaliados 80 implantes, separados em dois grupos, sendo 40 implantes instalados em pacientes com biótipo gengival fino (menor que $2 \mathrm{~mm}$ ) e 40 em pacientes com biótipo espesso (maior ou igual a $2 \mathrm{~mm}$ ). Todos os implantes utilizados foram do mesmo fabricante, com o mesmo diâmetro, com platform switching e instalados na mesma profundidade óssea (bone level). A média de remodelação no grupo com biótipo fino foi de $1,17 \mathrm{~mm}$ enquanto no grupo com biótipo grosso foi de $0,21 \mathrm{~mm}$ havendo diferença estatisticamente significante entre os grupos (LINKEVICIUS et al., 2015).

Em estudo recente, a divisão do biótipo gengival em fino (menor que $2 \mathrm{~mm}$ ) e espesso (maior que $2 \mathrm{~mm}$ ) como parâmetro dicotômico e sua correlação com a remodelação óssea marginal foi questionado, tendo em vista resultados que mostraram que a saucerização só pode ser minimizada quando a espessura gengival 
é maior ou igual a $3 \mathrm{~mm}$. Implantes instalados em biótipos até $2 \mathrm{~mm}$ apresentaram remodelação óssea semelhantes. Os autores sugerem então classificar o biótipo em fino, quando for menor que $2 \mathrm{~mm}$, médio quando for maior que 2 e menor que $3 \mathrm{~mm}$ e espesso, quando tiver $3 \mathrm{~mm}$ ou mais de espessura (LINKEVICIUS et al., 2018).

Uma revisão sistemática com meta-análise realizada em 2016, evidenciou a importância do biótipo gengival espesso na prevenção da remodelação óssea marginal ao redor dos implantes, sugerindo a utilização de técnicas cirúrgicas para aumento gengival em biótipos finos (SUÁREZ-LÓPEZ DEL AMO et al., 2016). Em estudo semelhante de revisão sistemática os autores também encontraram maior remodelação óssea em biótipos finos (AKCALI et al., 2016).

Em contrapartida, um estudo clínico e histológico não mostrou diferenças na remodelação óssea em pacientes com biótipos finos ou espessos (CANULLO et al., 2017).

Por outro lado, um estudo clínico prospectivo randomizado, sugere que a espessura gengival só interfere na remodelação óssea marginal, em casos onde os implantes foram instalados ao nível ósseo (bone level). Implantes instalados ao nível gengival (tissue level) apresentam uma pequena remodelação óssea sem diferenças estatísticas para os grupos de biótipo fino ou espesso (VAN EEKEREN et al., 2016)

Neste contexto, um grupo de pesquisadores investigou a remodelação óssea marginal peri-implantar em implantes com profundidades diferentes. Foram instalados 2 implantes adjacentes, sendo 1 ao nível crestal e 1 foi instalado $3 \mathrm{~mm}$ abaixo da margem gengival, ficando geralmente subcrestal. $O$ estudo encontrou menor remodelação nos implantes instalados $3 \mathrm{~mm}$ abaixo do nível gengival com diferença estatisticamente significante em relação ao grupo controle (VERVAEKE et al., 2018).

Porém aprofundar demais os implantes dentro do osso, afim de preservar um espaço para acomodação das distâncias biológicas, pode ser um problema, tendo em vista que a literatura sugere uma maior remodelação quando os implantes são instalados mais do que $3 \mathrm{~mm}$ para apical da junção amelo cementária dos dentes adjacentes (MAILOA et al., 2015).

Outro fator considerado relevante no processo de remodelação óssea periimplantar é a altura do intermediário protético. Um estudo clínico mostrou que quando 
utilizamos pilares com uma altura de transmucoso baixa (1 a $2 \mathrm{~mm}$ ) a remodelação óssea é maior que quando utilizamos pilares com $3 \mathrm{~mm}$ de altura (VERVAEKE et al., 2012). Em um estudo clínico os autores avaliaram 2 tipos de altura de transmucoso (1 e $3 \mathrm{~mm}$ ) e encontrou também maior remodelação óssea ao redor dos implantes com pilares mais baixo (BLANCO et al., 2017). Resultados semelhantes foram encontrados em outros trabalhos publicados com acompanhamento de até 3 anos (GALINDOMORENO et al., 2014; NÓVOA et al.,2017).

Um outro conceito bastante difundido, é o de que a instalação de um componente protético no ato da instalação do implante, possa preservar o tecido ósseo, já que não haveria uma desconexão constante de componentes próximo ao epitélio juncional. Entretanto, um estudo recente, comparou a remodelação óssea em três implantes adjacentes, sendo um implante instalado com abutment final durante o ato cirúrgico, em outro foi instalado cicatrizador e após período de osseointegração foi realizada a instalação do intermediário, e por último, um implante que foi realizado em dois tempos cirúrgicos, ficando submerso em um primeiro momento. Não houve diferença estatisticamente significante na perda óssea marginal entre os grupos (GIACOMEL et al., 2017). Um ensaio clínico randomizado com 24 pacientes divididos em 2 grupos, onde no primeiro grupo os pacientes receberam o implante e imediatamente foi instalado um abutment que não foi mais removido durante a fabricação da prótese e no segundo grupo os pacientes receberam o implante e um cicatrizador que foi removido e reinstalado por 3 vezes durante o processo de confecção da prótese. Houve uma pequena diferença na remodelação óssea apenas nos 2 primeiros meses, não havendo diferença estatisticamente significante na remodelação óssea para os 2 grupos transcorridos 6 meses (PRAÇA et al., 2020).

Em estudos histológicos em cães, pesquisadores verificaram que a remodelação óssea peri-implantar ocorreu tanto em implantes instalados subcrestais como nos instalados no nível da crista óssea, ocorreu ainda em implantes com ou sem platform switching, realizados em abordagem com retalho ou flap less (LEE et al., 2014; WENZEL et al., 2014; GAMBORENA et al., 2014).

Apesar do mercado estar caminhando para utilização de implantes com platform switching, a literatura tem mostrado, através de estudos retrospectivos de longo prazo (até 20 anos), que os implantes do tipo hexagonais externos, são uma boa opção, tendo uma média aceitável de remodelação óssea peri-implantar de 0.8 
$\mathrm{mm}$, completamente compatível com o padrão fisiológico de outras plataformas, desde que critérios adequados de instalação e posicionamento sejam respeitados (PIKNER et al., 2008).

Em outro estudo clínico avaliou-se 2010 implantes instalados em 1159 pacientes e não foram encontradas diferenças clínicas significantes entre implantes com conexão externa e interna (VIGOLO et al., 2016). Sendo assim, vale ressaltar que não parece haver evidência científica comprovada da superioridade de qualquer sistema de implante em termos de sucesso a longo prazo (ESPOSITO et al., 2014).

Considerando que na literatura tem sido demonstrada a importância de um biótipo gengival espesso para preservação óssea peri-implantar, enxertos de tecido conjuntivo ou outras técnicas para melhorar a qualidade dos tecidos moles periimplantares têm sido amplamente aplicadas (LEVINE et al., 2017; NOELKEN et al., 2018).

Sendo assim, fica evidente a importância de diagnosticar a espessura gengival previamente a instalação dos implantes dentários. Para tal diversos métodos podem ser utilizados, como o método transgengival, medição direta do retalho por sonda periodontal ou através de uma tomografia computadorizada com afastamento tecidual, sendo este último, um método confiável e útil clinicamente (ALVES et al., 2019). 
2 PROPOSIÇÃO 



\section{PROPOSIÇÃO}

Avaliar objetivamente a relação entre a espessura gengival e a remodelação óssea marginal peri-implantar, de implantes de conexão cônica interna submetidos a carga imediata com coroa metalocerâmica ou cerâmica hibrida com contato oclusal e abutment do tipo interface de titânio. 

3 MATERIAL e MÉtodos 



\section{MATERIAL E MÉTODOS}

\subsection{SELEÇÃO DA AMOSTRA}

O estudo clínico foi conduzido após aprovação no Comitê de Ética em Pesquisas em Seres Humanos da Faculdade de Odontologia de Bauru, Universidade de São Paulo (CAAE: 50811015.0.0000.5417 - anexo 1).

Foram selecionados 29 pacientes na clínica de Pós-Graduação da Faculdade de Odontologia de Bauru. Os indivíduos foram devidamente informados sobre os benefícios e riscos do estudo. Explicações completas sobre os tratamentos foram dadas, previamente ao início do estudo e todas as dúvidas dos pacientes foram sanadas, além de explicações sobre possíveis alternativas de tratamento. A participação no estudo só se iniciou após a assinatura de um termo de consentimento livre e esclarecido.

Os critérios de inclusão foram: pacientes com sítios edêntulos com indicação para instalação de 1 implante em região de molar ou pré-molar, altura e espessura suficientes para instalação de 1 implante de no mínimo $3.5 \mathrm{~mm}$ (diâmetro) x 8,5 mm (comprimento) que não fossem necessários procedimentos de enxertia óssea, 18 anos ou mais, não apresentar doença sistêmica que afete os tecidos periodontais nem o metabolismo ósseo (ASA I), presença de dentes adjacentes sem comprometimento periodontal e sem necessidade de tratamento restaurador e dentes antagonistas naturais e hígidos.

Foram excluídos do estudo pacientes com histórico de alcoolismo, fumantes ou usuários de drogas ilícitas, bem como cardiopatas, diabéticos, ou com necessidade de reabilitação oral com alteração do plano oclusal ou da dimensão vertical. Pacientes com indicação de enxertos ósseos também foram excluídos do estudo, assim como os portadores de hábitos parafuncionais, pacientes enxertados ou irradiados, usuários de bifosfonatos, periodontalmente comprometidos ou em tratamento ortodôntico, além dos pacientes onde o torque de instalação do implante não tenha sido igual ou superior a $32 \mathrm{~N}$. 
O planejamento protético prévio dos 29 pacientes foi realizado através de moldagem para confecção de uma guia cirúrgica. Os guias foram perfurados no centro da futura coroa protética e o espaço foi preenchido com guta percha. Todas as tomografias foram realizadas com afastamento dos lábios e bochechas conforme descrito em trabalhos anteriores para permitir a visualização da medida do biótipo gengival (ALVES et al., 2019) e com o guia em posição para permitir a visualização da posição ideal do implante. Os implantes foram selecionados de acordo com a disponibilidade óssea avaliada na tomografia. Foram utilizados implantes de 3.5, 4.3 e $5.0 \mathrm{~mm}$ de diâmetro e 8.5, 10, 11.5 e $13 \mathrm{~mm}$ de comprimento. Cada paciente recebeu 1 implante de conexão interna cônica (Unitite, S.I.N., São Paulo, Brasil).

\subsection{AVALIAÇÃO DO BIÓTIPO GENGIVAL}

O biótipo gengival foi avaliado em todos os pacientes durante o planejamento tomográfico (3D Accuitomo 170, Morita, Kyoto, Japão). Foi medida a espessura da gengiva no ponto central do guia tomográfico (Figura 1), referente a posição aproximada de onde foi instalado o implante. O método tomográfico foi escolhido por ser um método não invasivo, confiável (ALVES, et al., 2019) e pela tomografia já ter sido solicitada para planejamento do caso.

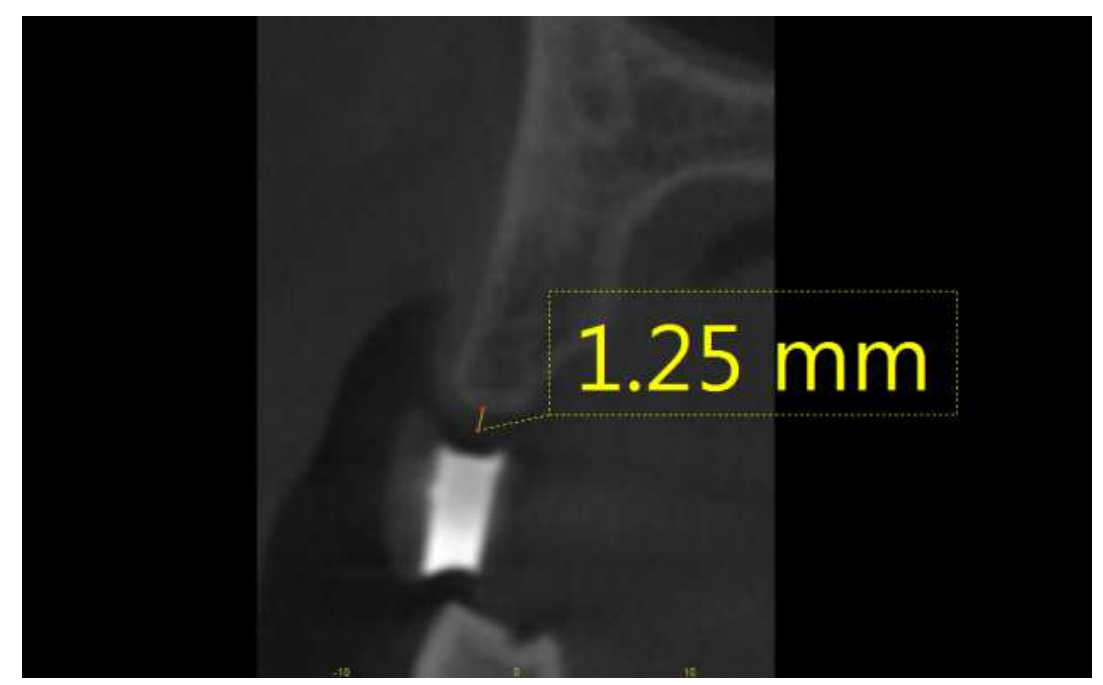

Figura 1 - Método de avaliação tomográfica do biótipo gengival 


\subsection{PROCEDIMENTOS CLÍNICOS}

Todas as cirurgias para instalação dos implantes foram realizadas por um único profissional, com experiência cirúrgica em implantodontia. As cirurgias foram realizadas sob anestesia local (cloridrato de mepivacaína 2\% com adrenalina a 1:100000 - Mepiadre 2\%, Nova DFL, Rio de Janeiro, RJ, Brasil). Foi realizado um retalho de espessura total para exposição do tecido ósseo. Em todos os pacientes foi realizado uma incisão ligeiramente para lingual/palatina com a finalidade de levar uma faixa de tecido queratinizado para vestibular, preservando um mínimo de $2 \mathrm{~mm}$ de queratinizada para cada lado. Os 29 implantes foram instalados seguindo a guia cirúrgica utilizada durante a tomografia para o correto posicionamento do mesmo. Todos os implantes foram instalados $3 \mathrm{~mm}$ abaixo do nível da guia cirúrgica (1 a $2 \mathrm{~mm}$ subcrestal, conforme necessidade e dependendo do biótipo gengival). A sequência de fresagem obedeceu a recomendação do fabricante (Unitite, S.I.N., São Paulo, São Paulo, Brasil). Todos os implantes obtiveram torque mínimo de $32 \mathrm{~N}$, mensurado pelo operador com torquímetro de catraca (S.I.N., São Paulo, Brasil). Suturas reabsorvíveis foram realizadas com Vicryl 5.0 (Ethicon J\&J International, St-Stevens-Woluwe, Belgium). Todos os pacientes foram medicados com 0 mesmo protocolo medicamentoso (Amoxicilina 500mg 3x ao dia por 7 dias e Ibuprofeno $600 \mathrm{mg} 3 \mathrm{x}$ ao dia por 5 dias).

Imediatamente após a cirurgia, foi realizada transferência dos implantes por meio de moldagem de arrasto (moldeira aberta) utilizando um silicone por adição (Express XT, 3M Oral Care, St Paul, MN, USA). Os arcos antagonistas foram moldados com o mesmo material. Após esta etapa, os implantes receberam um abutment de cicatrização e as moldagens foram enviadas ao laboratório para confecção das coroas (Digidental Solutions, São Paulo, SP, Brasil). Todas as moldagens passaram pelo mesmo processo para confecção do modelo de trabalho (colocação do análogo, aplicação de gengiva artificial e utilizado gesso pedra especial tipo IV).

Todas as coroas foram realizadas sobre uma interface em titânio de $2 \mathrm{~mm}$ de altura com a mesma altura de transmucoso $(2 \mathrm{~mm})$. As interfaces foram instaladas no modelo e digitalizadas através de um scanner de bancada (Scanner S600 ARTI, Zirkonzahn, Gais, Swiss). Os pacientes foram divididos em 2 grupos: Grupo 1, 
composto por 19 pacientes, receberam coroas metalocerâmicas, enquanto o Grupo 2, composto por 10 pacientes receberam coroas de uma cerâmica hibrida (Enamic, VITA, Bad Säckingen, Baden-Württemberg, Germany). As estruturas metálicas foram todas fresadas em metal sinterizado (Sintermetall, Zirkonzahn, Gais, Swiss) e sobre elas foi estratificado a cerâmica de cobertura (IPS InLine, Ivoclar Vivadent, Schann, Liechtenstein). Já no grupo 2, as coroas foram fresadas de forma monoíticas. As coroas foram cimentadas sobre as interfaces de titânio com cimento resinoso Panavia (Kuraray America, New York, NY, USA). Os excessos de cimento foram removidos fora da boca, e as coroas foram aparafusadas sobre os implantes 4 dias após a moldagem. Todas as peças passaram por ajustes do ponto de contato e ficaram com contatos oclusais em máxima intercuspidação e sem contato em lateralidade e protrusão. Todos os implantes foram radiografados após a instalação das coroas (T1) com auxílio de uma guia de resina para padronização da posição.

\subsection{AVALIAÇÃO DA REMODELAÇÃO ÓSSEA MARGINAL PERI-IMPLANTAR}

Foram feitas radiografias periapicais padronizadas de todas as coroas com 6 meses (T2) e 1 ano (T3), além das radiografias realizadas previamente (T1) para avaliação da remodelação óssea marginal peri-implantar. Foram realizadas medidas da cabeça do implante até o primeiro contato com tecido ósseo, na face mesial e distal. As medidas foram realizadas através do programa Image $J \otimes$ (National Institutes of Health, Bethesda, Maryland, USA). A medida do comprimento do implante foi utilizada para calibração das radiografias. A média da remodelação óssea entre mesial e distal foi utilizada.

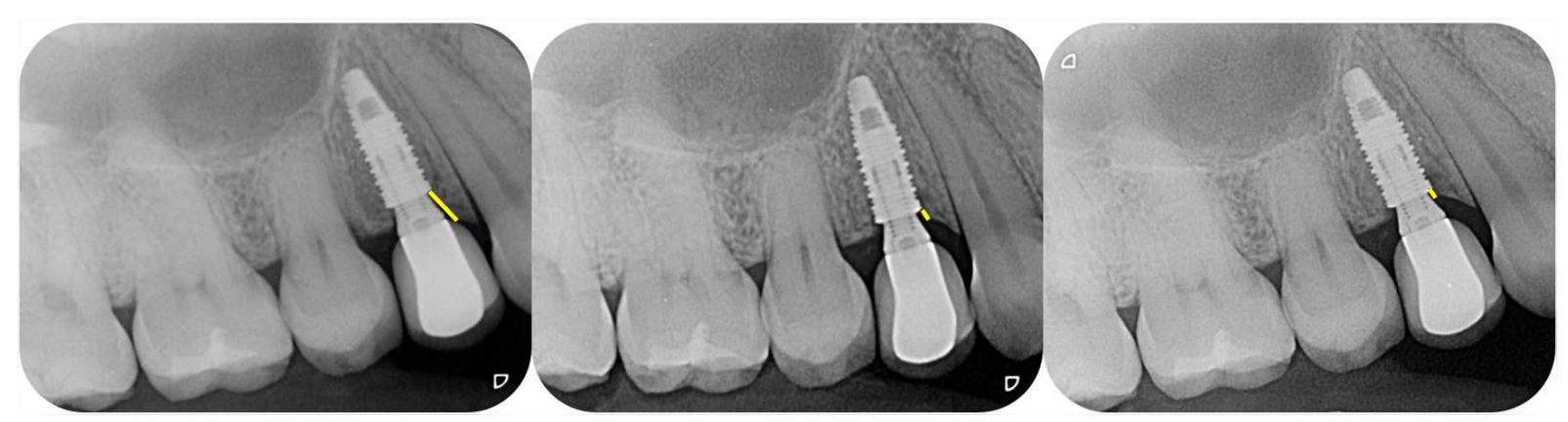

Figura 2 - Radiografias medindo o nível ósseo mesial em T1, T2 e T3 


\subsection{ANÁLISE ESTATÍSTICA}

Os dados obtidos referentes ao biótipo gengival e a remodelação óssea marginal peri-implantar em T1, T2 e T3 foram inseridas em uma planilha do Excel (Microsoft Corporation, USA), onde foram processados estatisticamente.

Os resultados foram analisados por um estatístico sem participação na coleta de dados e etapas clínicas da pesquisa. As médias e desvio padrão foram calculados e tabulados. O teste de Kolmogorov-Smimov e Shapiro-Wilk foram aplicados como testes de normalidade das variáveis. O teste de Tukey foi utilizado para comparar o nível ósseo em T1, T2 e T3. Para avaliação das médias e desvio padrão da remodelação óssea, o Teste-t pareado foi aplicado. Já para correlação entre biótipo gengival e remodelação óssea o coeficiente de correlação Pearson foi utilizado e os valores de referência considerados para as correlações foram: (r) -1 a 1 sendo valores até 0,30 considerados fracos, entre 0,40 e 0,6 moderados e acima disso considerados fortes. Valores negativos reproduzem correlação inversamente proporcional, enquanto positivos reproduzem correlação diretamente proporcional.

O nível de significância adotado foi de $5 \%(p>0,05)$. 

4 Resultados 



\section{RESULTADOS}

Foram incluídos no estudo 29 pacientes, sendo o Grupo 1 os pacientes que receberam uma coroa metalocerâmica $(n=19)$ e o Grupo 2 pacientes que receberam uma coroa de cerâmica híbrida $(n=10)$. Todos os implantes foram instalados em região posterior (pré-molares e molares da maxila ou da mandíbula). Todos os implantes atingiram torque mínimo de $32 \mathrm{~N}$ e pacientes que não atingiram este parâmetro durante a cirúrgica, foram excluídos do estudo e reabilitados em 2 tempos cirúrgicos.

Os 19 implantes do Grupo 1 foram instalados para substituírem 9 molares, sendo 8 na mandíbula e 1 na maxila e 10 pré-molares, sendo 8 na maxila e 2 na mandíbula. Enquanto no Grupo 2 os 10 implantes foram instalados para substituir 4 molares (todos em mandíbula) e 6 pré-molares (4 na maxila e 2 em mandíbula).

Os participantes foram monitorados por um período de 1 ano.

As médias e desvio padrão do nível ósseo em T1, T2 e T3 bem como a remodelação óssea marginal que ocorreu neste período estão na tabela 1 , além da média e desvio padrão da espessura gengival, para o grupo metalocerâmica (Grupo 1). A tabela 2, mostra os mesmos dados para o grupo Enamic (Grupo 2)

Tabela 1 - Média e desvio padrão do nível ósseo e espessura gengival para o Grupo 1

\begin{tabular}{cc|c|c|c}
\hline Variáveis & Média & Desvio padrão & Mínimo & Máximo \\
\hline Nível ósseo T1 & 1.60 & 0.32 & 1.13 & 2.21 \\
\hline Nível ósseo T2 (6 meses) & 0.41 & 0.62 & -0.80 & 1.35 \\
\hline Remodelação óssea em T2 & 1.19 & 0.56 & 0.33 & 2.32 \\
\hline Nível ósseo T3 (1 ano) & 0.29 & 0.68 & -1.08 & 1.35 \\
\hline Remodelação óssea em T3 & 1.31 & 0.54 & 0.31 & 2.42 \\
\hline Espessura gengival & 1.74 & 0.89 & 0.25 & 3.10 \\
\hline
\end{tabular}


Tabela 2 - Média e desvio padrão do nível ósseo e espessura gengival para o Grupo 2

\begin{tabular}{cc|c|c|c}
\hline Variáveis & Média & $\begin{array}{c}\text { Desvio } \\
\text { padrão }\end{array}$ & Mínimo & Máximo \\
\hline Nível ósseo T1 & 1.32 & 0.37 & 0.86 & 1.96 \\
\hline Nível ósseo T2 (6 meses) & 0.81 & 0.45 & 0.21 & 1.46 \\
\hline Remodelação óssea em T2 & 0.51 & 0.56 & -0.27 & 1.33 \\
\hline Nível ósseo em T3 (1 ano) & 0.64 & 0.38 & 0.15 & 1.44 \\
\hline Remodelação óssea em T3 & 0.68 & 0.47 & 0.12 & 1.40 \\
\hline Espessura gengival & 2.23 & 0.71 & 0.89 & 3.03 \\
\hline
\end{tabular}

A tabela 3 e 4 comparam o nível ósseo nos 3 tempos (teste de Tukey) para ambos os grupos

Tabela 3 - Comparação do nível ósseo nos 3 tempos (ANOVA a um critério para medidas repetidas e Teste de Tukey) para o Grupo 1

$\begin{array}{cccccc}\text { Tukey } & \text { TEMPO } & \text { T1 } & \text { T2 } & \text { T3 } \\ \mathbf{1} & \text { T1 } & & 0.000125 & 0.000125 \\ \mathbf{2} & \text { T2 } & 0.000125 & & 0.564164 \\ \mathbf{3} & \text { T3 } & 0.000125 & 0.564164 & \end{array}$

Tabela 4 - Comparação do nível ósseo nos 3 tempos (ANOVA a um critério para medidas repetidas e Teste de Tukey) para o Grupo 2

\begin{tabular}{c|cccc} 
& TEMPO & T1 & T2 & T3 \\
\hline $\mathbf{1}$ & T1 & & 0.004763 & 0.000424 \\
$\mathbf{2}$ & T2 & 0.004763 & & 0.439633 \\
$\mathbf{3}$ & T3 & 0.000424 & 0.439633 &
\end{tabular}

As tabelas 5 e 6 mostram a média e o desvio padrão da remodelação óssea marginal peri-implantar nos tempos T2 e T3 para os grupos. 
Tabela 5 - média e desvio padrão da remodelação óssea para o grupo 1

\begin{tabular}{c|cccc} 
& Média & Desvio padrão. & Diferença & $\mathbf{p}$ \\
\hline Remodelação T2 & 1.19 & 0.56 & & \\
Remodelação T3 & 1.30 & 0.54 & -0.12 & 0.16 \\
\hline Diferença & $10.0 \%$ & & & \\
\hline
\end{tabular}

Tabela 6 - média e desvio padrão da remodelação óssea para o Grupo 2

\begin{tabular}{ccccc} 
& Média & Desvio Padrão & Diferença & p \\
\hline Remodelação T2 & 0.50 & 0.56 & & \\
Remodelação T3 & 0.68 & 0.47 & -0.17 & 0.01 \\
\hline Diferença & $34.0 \%$ & & &
\end{tabular}

A tabela 7 apresenta a comparação o nível ósseo e a quantidade de remodelação que ocorreu nos dois grupos (Teste $\mathrm{t}$ ).

Tabela 7 - comparação do nível ósseo e quantidade de remodelação em ambos os grupos

\begin{tabular}{ccc|c|c|c} 
& Grupo & $\mathbf{N}$ & Média & Erro Desvio & $\begin{array}{c}\text { Erro padrão da } \\
\text { média }\end{array}$ \\
\hline Nível ósseo T1 & $\mathbf{1}$ & 19 & 1.60 & 0.32 & 0.08 \\
\hline Nível ósseo T2 & $\mathbf{2}$ & 10 & 1.32 & 0.37 & 0.12 \\
\hline Remodelação T2 & $\mathbf{1}$ & 19 & 0.41 & 0.62 & 0.15 \\
\hline Nível ósseo T3 & $\mathbf{1}$ & 10 & 0.81 & 0.45 & 0.14 \\
\hline Remodelação T3 & $\mathbf{2}$ & 19 & 1.19 & 0.56 & 0.13 \\
\hline & $\mathbf{1}$ & 10 & 0.51 & 0.56 & 0.18 \\
\hline Espessura gengival & $\mathbf{1}$ & 10 & 0.29 & 0.68 & 0.16 \\
\hline & $\mathbf{1}$ & 19 & 1.31 & 0.54 & 0.12 \\
\hline & $\mathbf{2}$ & 10 & 0.68 & 0.47 & 0.13 \\
\hline
\end{tabular}


A tabela 8 e 9 correlaciona (Coeficiente de correlação de Pearson) a remodelação óssea com a espessura gengival nos grupos 1 e 2 respectivamente.

Tabela 8 - Correlação entre remodelação óssea e espessura gengival para o Grupo 1

\begin{tabular}{cc|c|c} 
& & Remodelação T2 & Remodelação T3 \\
\hline Espessura gingival Grupo 1 & $\mathbf{r}$ & -0.37 &,$- 49^{*}$ \\
\hline & $\mathbf{p}$ & $\mathbf{0 . 1 3}$ & $\mathbf{0 . 0 4}$ \\
\hline $\mathbf{N}$ & 19 & 19
\end{tabular}

Tabela 9 - Correlação entre remodelação óssea e espessura gengival para o grupo 2

\section{Remodelação T2 Remodelação T3}

\begin{tabular}{cccc}
\hline Espessura gingival Grupo 2 & $\mathbf{r}$ & $-0,69$ &,$- 681^{*}$ \\
\hline & $\mathbf{p}$ & $\mathbf{0 . 0 3}$ & $\mathbf{0 . 0 3}$ \\
\hline $\mathbf{N}$ & 10 & 10
\end{tabular}


5 DISCUSSÃO 



\section{DISCUSSÃO}

A remodelação óssea marginal peri-implantar foi descrita há muitos anos e desde então estudos foram realizados para entender este fenômeno fisiológico. Acreditou-se que no primeiro ano em função a remodelação óssea marginal era de aproximadamente 1.5 a $2 \mathrm{~mm}$ e de $0,2 \mathrm{~mm}$ ao ano de forma continua e progressiva (ALBREKTSSON, et al., 1986). Atualmente busca-se maneiras de minimizar esta remodelação inicial e já está consolidado na literatura que ela deve se estabilizar, não sendo progressiva, a menos que haja colonização bacteriana e uma peri-implantite acometa esta região (COLI et al, 2017).

Os resultados deste estudo evidenciaram que a utilização de um implante de conexão cônica interna (platform switching), sem desconexão de componentes não foi suficiente para evitar a remodelação óssea peri-implantar para ambos os Grupos. Nossos resultados contrariam estudos anteriores (PERROTTI et al., 2019) que evidenciaram que o conceito one-abutment at one-time seria um importante fator na preservação do osso marginal ao redor de implantes. Nossos resultados também contrastam com diversos estudos (ATIEH et al., 2010; AL-NSOUR et al, 2012; HEREKAR et al, 2014; STRIETZEL et al, 2015; SANTIAGO Jr et al, 2015; MEDEIROS et al., 2016; CARICASULO et al., 2017;) que relatam ser possível minimizar a remodelação óssea quando utilizamos implantes com conceito de platform switching. Nossos resultados corroboram, porém, com os achados em outros estudos (GIACOMEL et al., 2017; PRAÇA et al., 2020) que relatam não haver diferença significativa na remodelação óssea, quando componentes protéticos são desconectados e reconectados ao implante nem quando utilizamos implantes com platform switching (ESPOSITO et al., 2016).

Apesar de muitos estudos atuais relatarem uma remodelação óssea inferior aos $2 \mathrm{~mm}$, este processo parece ocorrer em todos os implantes a despeito dos tipos de materiais restauradores, tipos de intermediários protéticos utilizados e estratégias cirúrgicas e protéticas adotadas com o objetivo de evitá-la. Atualmente não existe na literatura nenhum estudo comprovando que seja possível evitar a remodelação óssea marginal após a instalação de um implante, apesar de vários estudos mostrarem 
perdas muito próximas a zero, principalmente quando o biótipo gengival é espesso (LINKEVICIUS et al., 2015).

A remodelação óssea marginal ao redor de implantes é uma reação fisiológica do organismo com o intuito de estabelecer um espaço para a acomodação das distâncias biológicas, preservando a homeostasia da região através de uma barreira biológica de tecido mole (COCHRAN, et al., 1997). Dessa maneira, ao instalarmos um implante próximo a crista óssea, o mesmo funcionaria como um agente invasor das distâncias biológicas fazendo com que estas migrem para apical permitindo assim a acomodação dos tecidos peri-implantares e consequentemente a homeostasia marginal destes tecidos. Apesar de pequenas diferenças, a literatura já evidenciou a necessidade de 3 a $4 \mathrm{~mm}$ de tecido gengival para acomodação das estruturas que compõe as distâncias biológicas peri-implantares. Caso esta espessura mínima não esteja presente, o tecido ósseo sofrerá remodelação para criar este espaço (BERGLUNDH; LINDHE, 1996). Isto explicaria o motivo para haver remodelação óssea mesmo em implantes com conexões estáveis e utilizando o conceito oneabutment at one-time (CRESPI et al., 2009).

Dessa maneira, vários autores têm demonstrado que a única maneira efetiva de reduzir a remodelação óssea peri-implantar é instalar implantes em áreas com tecido gengival espesso, ou em casos de tecido fino, realizar procedimentos cirúrgicos para alterar esta condição desfavorável (LINKEVICIUS, et al, 2009; LINKEVICIUS, et al, 2010; PUISYS; LINKEVICIUS, 2015; LINKEVICIUS, et al, 2015; LINKEVICIUS, et al 2018). Apesar destes estudos terem evidenciado que o biótipo gengival é um importante fator associado a melhor preservação óssea marginal ao redor dos implantes, a maioria deles avalia a espessura gengival de maneira direta através de uma sonda periodontal com o retalho descolado, o que não permite avaliar espessuras menores que $1 \mathrm{~mm}$, além de dividir o grupo de maneira dicotômica em fino ou espesso. Em nosso trabalho, por termos utilizado um método objetivo de avaliação da espessura gengival e utilizado um número exato para correlação, resultados mais confiáveis podem ser encontrados.

Em nosso estudo, a despeito da utilização de implantes de conexão cônica interna, com platform switching, seguindo os princípios do conceito one-abutment at one-time e um componente protético do tipo ti-base, que não sofreu nenhum tipo de processo de fundição, que poderia alterar a correta adaptação do mesmo, 
observamos uma remodelação óssea peri-implantar média de 1,31 mm para o Grupo 1 e 0,68 mm para o Grupo 2, após 1 ano em função. Resultados estes semelhantes ao encontrado em estudo anterior (GIACOMEL et al., 2017) e ligeiramente maiores que os descritos por outros estudos (LAURELL; LUNDGREN, 2011; CASSETTA, et al., 2016; GUVEN, et al., 2020; COLI, et al, 2017). Esta diferença pode ser explicada pela heterogeneidade da amostra, ou por alguns estudos considerarem o tempo inicial de avaliação da remodelação óssea marginal a partir do tempo de instalação da coroa final, desconsiderando que durante a utilização de cicatrizadores ou provisórios, esta remodelação já pode ocorrer. Em nosso estudo a avaliação do nível ósseo foi (T1) foi realizada em menor tempo, tendo em vista que os implantes foram submetidos a carga imediata.

Vale ressaltar que em nossos resultados, apesar da remodelação óssea ter ocorrido, a maioria dos pacientes, ficaram com o nível ósseo coronal a cabeça do implante, devido ao posicionamento subcrestais dos mesmos. Outros estudos (CASSETA et al., 2016) que posicionem os implantes com a mesma profundidade, mas avalie a remodelação óssea após alguns meses, pode considerar que ela não tenha ocorrido devido a posição continuar coronal a plataforma do implante.

Apesar de alguns estudos terem relatado melhor preservação do nível ósseo peri-implantar em implantes que receberam abutments com transmucosos mais altos (GALINDO-MORENO, et al, 2014; VERVAEKE, et al, 2014), talvez esse resultado esteja relacionado ao fato de geralmente utilizarmos componentes mais altos quando temos um tecido gengival espesso e não ao fato isolado de utilizarmos este tipo de componente. Em nosso estudo, mesmo utilizando um pilar com $2 \mathrm{~mm}$ de altura de transmucoso, a remodelação óssea ocorreu.

Com relação ao conceito de platform switching, a despeito de a literatura relatar potenciais efeitos benéficos (ATIEH et al., 2010; HEREKAR et al, 2014; STRIETZEL et al, 2015; SANTIAGO Jr et al, 2015; MEDEIROS et al., 2016; CARICASULO et al., 2017), os resultados são controversos e nenhuma conclusão clara pode ser tomada neste momento (ENKLING et al., 2013; LIN et al., 2013; STRIETZEL et al, 2015; ESPOSITO et al., 2016) tendo em vista que vários estudos falharam em demonstrar esta melhor preservação óssea na presença de um tecido gengival fino (LINKEVICIUS, et al, 2010; LINKEVICIUS, et al, 2015; SUÁREZ-LÓPEZ DEL AMO et al., 2016). 
Este estudo objetivou mostrar a remodelação óssea peri-implantar ocorrida em pacientes submetidos a carga imediata com a coroa final em oclusão em máxima intercuspidação com coroas metalocerâmicas e cerâmicas hibrídas e correlacionar esta remodelação com a espessura gengival diagnosticada através de uma tomografia computadorizada. Em ambos os grupos, houve diferença estatisticamente significante na perda óssea entre o T1 e o T3. Estudo longitudinal com maior tempo de avaliação destes pacientes devem ser realizados para verificar se o nível ósseo irá se estabilizar após esta remodelação inicial.

Estatisticamente no Grupo 1, houve uma remodelação maior que no Grupo 2. Este fato pode ter ocorrido devido as características diferentes do material restaurador ou ainda a espessura gengival média encontrada em ambos os grupos (1,74 mm no Grupo 1 e 2,23mm no Grupo 2), tendo em vista que a espessura gengival média encontrada no Grupo 1 é ligeiramente menor que no Grupo 2. Em caso de somarmos a espessura gengival média com a remodelação óssea média de ambos os grupos, teremos aproximadamente os $3 \mathrm{~mm}$ inerentes ao espaço biológico peri-implantar. $\mathrm{O}$ fato de as distâncias biológicas periodontais e peri-implantares serem variáveis, pode explicar o motivo de alguns implantes remodelarem mais ou menos osso após estarem em função. Sendo assim, talvez a posição de $4 \mathrm{~mm}$ abaixo do nível gengival possa preservar melhor o tecido ósseo, tendo em vista que na literatura, poucos trabalhos sugerem que as distâncias biológicas possam ser maiores que isso, e caso a remodelação ocorra, o nível da crista óssea permanecerá coronal a plataforma do implante, minimizando complicações futuras.

Os resultados de nosso estudo mostram uma correlação moderada entre a remodelação óssea peri-implantar e a espessura gengival para o Grupo $1(r=-495)$ e uma correlação forte para o Grupo 2 ( $r=-681)$ corroborando com vários estudos atuais que relatam a importância da qualidade e espessura gengival ao redor de implantes para melhor preservação óssea marginal (LINKEVICIUS et al., 2009; LINKEVICIUS et al., 2010; LINKEVICIUS et al., 2013; PUISYS et al., 2015; LINKEVICIUS et al., 2015; AKCALI et al., 2016; SUÁREZ-LÓPES DEL AMO et al., 2016; LINKEVICIUS et al., 2018). 
6 CONCLUSÃo 



\section{CONCLUSÃO}

- O acompanhamento de 1 ano de implantes posteriores e unitários, de conexão cônica interna, submetidos a carga imediata com contato oclusal em máxima intercuspidação e componentes do tipo ti-base não evitaram a remodelação óssea marginal peri-implantar;

- Há de moderada a forte correlação entre a remodelação óssea marginal peri-implantar e a espessura gengival. 



\section{REFERÊNCIAS}





\section{REFERÊNCIAS}

AKCALI, A.; TRULLENQUE-ERIKSSON, A.; SUN, C.; PETRIE, A.; NIBALI, L.; DONOS, N. What is the effect of soft tissue thickness on crestal bone loss around dental implants? A systematic review. Clin Oral Implants Res, v. 28, n. 9, p. 1046-53, 2016.

ALBREKTSSON, T.; ZARB, G.; WORTHINGTON, P.; ERIKSSON, A.R. The long-term efficacy of currently used dental implants: a review and proposed criteria of success. Int J Oral Maxillofac Implants, v. 1, n. 1, p. 11-25, 1986

AL-NSOUR, M.M.; CHAN, H.L.; WANG, H.L. Effect of the platform-switching technique on preservation of peri-implant marginal bone: a systematic review. Int $\mathbf{J}$ Oral Maxillofac Implant, v. 27, n. 1, p. 138-45, 2012.

ALVES, P.H.M.; ALVES, T.C.L.P.; PEGORARO, T.A.; COSTA, Y.M.; BONFANTE, E.A.; DE ALMEIDA, A.L.P.F. Measurement properties of gingival biotype evaluation methods. Clin Implant Dent Relat Res, v. 20, n. 3, p. 280-84, 2018.

ATIEH, M.A.; ATIEH, A.H.; PAYNE, A.G.; DUNCAN, W.J. Immediate loading with single implant crowns: a systematic review and meta-analysis. Int J Prosthodont, v. 22 , n. 4, p. 378-87, 2009.

BERGLUNDH, T.; LINDHE, J. Dimension of the periimplant mucosa. Biological Width revisited. J Clin Periodontol, v. 23, n. 10, p. 971-3, 1996.

BLANCO, J.; PICO, A.; CANEIRO, L.; NÓVOA, L.; BATALLA, P.; MARTÍNLANCHARRO, P. Effect of aburment height on interproximal implant bone level in the early healing: a randomized clinical trial. Clin Oral Implants Res, v. 29, n. 1, p. 10817, 2017.

BROGGINI, N.; MCMANUS, L.M.; HERMANN, J.S.; MEDINA, R.U.; OATES, T.W.; SCHENK, R.K.; BUSER, D.; MELLONIG, J.T.; COCHRAN, D.L. Persistent acute inflammation at the implant-abutment interface. J Dent Res, v. 82, n. 3, p. 232-7, 2003.

CANEVA, M.; SALATA, L.A.; DE SOUZA, S.S.; BAFFONE, G.; LANG, N.P.; BOTTICELLI, D. Influence of implant positioning in extraction sockets on osseointegration: histomorphometric analyses in dogs. Clin Oral Implants Res, v. 21, n. 1, p. 43-9, 2010. 
CANULLO, L.; CAMACHO-ALONSO, F.; TALLARICO, M.; MELONI, S.M.; XHANARI, E.; PENARROCHA-OLTRA, D. Mucosa thickness and peri-implant crestal bone stability: a clinical and histologic prospective cohort trial. Int J Oral Maxillofac Implants, v. 32, n. 5, p. 675-81, 2017.

CARICASULO, R.; MALCHIODI, L.; GHENSI, P.; FANTOZZI, G.; CUCCHI, A. The influence of implant-abutment connection to peri-implant bone loss: a systematic review and meta-analysis. Clin Implant Dent Relat Res, v. 20, n. 4, p. 653-64, 2018.

CASSETTA, M.; DRIVER, A.; BRANDETTI, G.; CALASSO, S. Peri-implant bone loss around platform-switched morse taper connection implants: a prospective 60-month follow-up study. Int J Oral Maxillofac Surg, v. 45, n. 12, p. 1577-85, 2016.

COCHRAN, D.L.; HERMANN, J.S.; SCHENK, R.K.; HIGGINBOTTOM, F.L.; BUSER, D. Biologic width around titanium implants. A histometric analysis of the implantgingival junction around unloaded and loaded nonsubmerged implants in the canine mandible. J Periodontol, v.68, n. 2, p. 186-98, 1997.

COESTA, P.T.G. A extensão das distâncias biológicas do periodonto marginal: comparações clínicas e radiográficas. Dissertação de mestrado - Faculdade de Odontologia de Bauru, Universidade de São Paulo, Bauru, 2003.

COLI, P.; CHRISTIAENS, V.; SENNERBY, L.; BRUYN, H. Reliability of periodontal diagnostic tools for monitoring peri-implant health and disease. Periodontol 2000, v. 73, n.1, p. 203-17, 2017.

CRESPI, R.; CAPPARE, P.; GHERLONE, E. Radiographic evaluation of marginal bone levels around platform-switched and non-platform-switched implants used in an immediate loading protocol. Int J Oral Maxillofac Implants, n. 24, n. 5, p. 920-6, 2009.

DE MEDEIROS, R.A.; PELLIZZER, E.P.; VECHIATO FILHO, A.J.; DOS SANTOS, D.M.; DA SILVA, E.V.; GOIATO, M.C. Evaluation of marginal bone loss of dental implants with internal or external connections and its association with other variables: a systematic review. J Prosthet Dent, v. 116, n. 4, p. 501-06, 2016.

DIAS, E.C.; BISOGNIN, E.D.; HARARI, N.D.; MACHADO, S.J.; DA SILVA, C.P.; SOARES, G.D.; VIDIGAL, G.M. Jr. Evaluation of implant-abutment microgap and bacterial leakage in five external-hex implant systems: an in vitro study. Int $\mathbf{J}$ Oral Maxillofac Implants, v. 27, n. 2, p. 346-51, 2012.

ENKLING, N.; JOHREN, P.; KATSOULIS, J.; BAYER, S.; JERVOE-STORM, P.M.; MERICSKE-STERN, R.; JEPSEN, S. Influence of platform switching on bone-level alterations: a three-year randomized clinical trial. J Dent Res, v. 92, n. 12, p. 139-45, 2013. 
ESPOSITO, M.; MAGHAIREH, H.; PISTILLI, R.; GRUSOVIN, M.G.; LEE, S.T.; TRULLENQUE-ERIKSSON, A.; GUALINI, F. Dental implats with internal versus external connections: 5-year post-loading results from a pragmatic multicenter randomised controlled trial. Eur J Oral Implantol, v. 1, n. 2, p. 129-41, 2016.

GAMBORENA, I.; LEE, J.; FIORINI, T.; WENZEL, B.A.; SCHUPBACH, P.; WIKESJO, U.M.; SUSIN, C. Effect of plarform shift/switch and concave abutments on crestal bone levels and mucosal profile following flap and flapless implant surgery. Clin Implant Dent Relat Res, v. 17, n. 5, p. 908-16, 2014.

GARGIULO, A.W.; WENTZ, G.M.; ORBAN, B. Dimensions and relations of the dentogingival junction in human. J Periodontol, v. 32, n. 3, p. 261-67, 1961.

GARLINDO-MORENO, P.; LEÓN-CANO, A.; MONJE, A.; ORTEGA-OLLER, I.; O'VALLE, F.; CATENA, A. Abutment height influences the effect of platform switching on peri-implant marginal bone loss. Clin Oral Implants Res, v. 27, n. 2, p. 167-73, 2016.

GIACOMEL, M.C.; CAMATI, P.; SOUZA, J.; DELIBERADOR, T. Comparison of marginal bone level changes of immediately loaded implants, delayed loaded nonsubmerged implants, and delayed loaded submerged implants: a randomized clinical trial. Int J Oral Maxillofac Implants, v. 33, n. 3, p. 661-6, 2017.

GUVEN, S.S.; CABBAR, F.; GULER, N. Local and systemic factors associated with marginal bone loss around dental implants: a retrospective clinical study. Quintessence Int, v. 51, n. 2, p. 128-41, 2020.

HEREKAR, M.; SETHI, M.; MULANI, S.; FERNANDES, A.; KULKARNI, H. Influence of platform switching on periimplant bone loss: A systematic review and meta-analysis. Impant Dent, v. 23, n. 4, p 439-50, 2014.

LAURELL, L.; LUNDGREN, D. Marginal bone level changes at dental implants after 5 years in function: a meta-analysis. Clin Implant Dent Relat Res, v 13, n. 1, p. 19-28, 2011.

LAZZARA, R.J.; PORTER, S.S. Platform switching: a new concept in implant dentistry for controlling postrestorative crestal bone levels. Int J Periodontics Restorative Dent, v. 26, n. 1, p. 9-17, 2006.

LEE, J.; FIORINI, T.; BAMBORENA, I.; WENZEL, B.A.; SCHUPBACH, P.; WIKESJO, U.M.; SUSIN, C. Effect of Platform Shift/Switch on Crestal Bone Levels and Mucosal Profile Following Flapless Surgery and Crestal/Subcrestal Implant Placement. Clin Implant Dent Relat Res, v. 18, n. 1, p. 73-81, 2014. 
LEVINE, R.A.; GANELES, J.; KAN, J.; FAVA, P.L. 10 keys for successful esthetic-zone single implants: importance of biotype conversion for lasting success. Compend Contin Educ Dent, v. 39, n. 8, p. 522-529, 2018.

LIN, M.I.; SHEN, Y.W.; HUANG, H.L.; HSU, J.T.; FUH, L.J. A retrospective study of implant abutment connections on crestal bone level. J Dent Res, v. 92, n. 12, p. 2027, 2013.

LINKEVICIUS, T.; APSE, P. Biologic width around implants. An evidence-based review. Stomatologija, v. 10, n. 1, p. 27-35, 2008.

LINKEVICIUS, T.; APSE, P.; GRYBAUSKAS, S.; PUISYS, A. Influence of thin mucosal tissues on crestal bone stability around implants with platform switching: a 1-year pilot study. J Oral Maxillofac Surg, v. 68, n. 9, p. 2272-7, 2010.

LINKEVICIUS, T.; APSE, P.; GRYBAUSKAS, S.; PUISYS, A. The influence of soft tissue thickness on crestal bone changes around implants: a 1-year prospective controlled clinical trial. Int J Oral Maxillofac Implants, v. 24, n. 4, p. 712-9.

LINKEVICIUS, T.; LINKEVICIUS, R.; ALKIMAVICIUS, J.; LINKEVICIENE, L.; ANDRIJAUSKAS, P.; PUISYS, A. Influence of titanium base, lithium dissilicate restoration and vertical soft tissue thickness on bone stability around triangular-shaped implants: a prospective clinical trial. Clin Oral Implants Res, v. 29, n. 7, p. 716-724, 2018.

LINKEVICIUS, T.; PUISYS, A.; LINKEVICIENE, L.; PECIULIENE, V.; SCHLEE, M. Crestal bone stability around implants with horizontally matching connection after soft tissue thickening: a prospective clinical trial. Clin Implant Dent Relat Res, v. 17, n. 3, p. $497-508,2013$

LINKEVICIUS, T.; PUISYS, A.; STEIGMANN, M.; VINDASIUTE, E,; LINKEVICIENE, $\mathrm{L}$. Influence of vertical soft tissue thickness on crestal bone changes around inplanst with platform switching: a comparative clinical study. Clin Implant Dent Relat Res, v. 17, n. 6, p. 1228-36, 2015.

MAILOA, J.; FU, J.H.; CHAN, H.L.; KHOSHKAM, V.; LI, J.; WANG, H. L. The effect of vertical implant position in relation to adjacent teeth on marginal bone loss in posterior arches: a retrospective study. Int J Oral Maxillofac Implants, v. 30, n. 4, p. 931-6, 2015.

MELONI, S.M.; DE RIU. G.; PISANO, M.; TULLIO, A. Immediate versus delayed loading of single mandibular molars. One year results from a randomised controlled trial. Eur J Oral Implantol, v. 5, n. 4, p. 345-53, 2012. 
MENDONÇA, J.A.G. Avaliação e análise das distâncias biológicas do periodonto mediante nova metodologia. Tese de doutorado - Faculdade de Odontologia de Bauru, Universidade de São Paulo, Bauru, 2001.

NOELKEN, R.; MOERGEL, M.; PAUSCH, T.; KUNKEL, M.; WAGNER, W.; Clinical and esthetic outcome with immediate insertion and provisionalization with or without connective tissue grafting in presence of mucogingival recessions: a retrospective analysis with follou-up between 1 and 8 years. Clin Implant Dent Relat Res, v. 20, n. 3, p. 285-93, 2018.

NÓVOA, L.; BATALLA, P.; CANEIRO, L.; PICO, A.; LIÑARES, A.; BLANCO, J. Influence of abutment height on maintenance of peri-implant crestal bone at bone-level implants: a 3-Year follow-up study. Int J Periodontics Restorative Dent, v. 37, n. 5, p. 721-27, 2017.

PARMA-BENFENATI, S.; FUGAZZOTO, P.A.; RUBEN, M.P. The effect of restorative margins on the postsurgical development and nature of the periodontium. Part I. Int $\mathbf{J}$ Periodontics Restorative Dent, v. 5, n. 6, p. 30-51, 1985.

PARMA-BENFENATI, S.; FUGAZZOTTO, P.A.; FERREIRA, P.M.; RUBEN, M.P.; KRAMER, G.M. The effect of restorative margins on the postsurgical development and nature of the periodontium. Part II. Int J Periodontics Restorative Dent, v. 6, n. 1, p. 64-75, 1986.

PERROTTI, V.; ZHANG, D.; LIANG, A.; WONG, J.; QUARANTA, A. The effect of oneabutment at one-time on marginal bone loss around implants placed in healed bone: a systematic review of human studies. Implant Dent, v. 28, n. 6, p. 603-12, 2019.

PETKOVIC, A.B.; MATIC, S.M.; STAMATOVIC, N.V.; VOJVODIC, D.V.; TODOROVIC, T.M.; LAZIC, Z.R.; KOZOMARA, R.J. Proinflammatory cytokines (IL1 beta and TNF-Alpha) and chemokines (IL-8 and MIP-1alpha) as markers of periimplant tissue condition. Int J Oral Maxilofac Surg, v. 39, n. 5, p. 478-85, 2010.

PIKNER, S.S.; GRONDAHL, K.; JEMT, T.; FRIBERG, B. Marginal bone loss at implants: a retrospective, long-term follow-up of turned Branemark System implants. Clin Implant Dent Relat Res, v. 11, n. 1, p. 11-23, 2008.

PRAÇA, L.F.G.; TEIXEIRA, R.C.; REGO, R.O. Influence of abutment disconnection on peri-implant marginal bone loss: a randomized clinical trial. Clin Oral Implants Res, doi:10.1111/clr.13572 [Epub ahead of print], 2020.

PUISYS, A.; LINKEVICIUS, T. The influence of mucosal tissue thickening on crestal bone stability around bone-level implants. A prospective controlled clinical trial. Clin Oral Implants Res, v. 26, n. 2, p. 123-9, 2013. 
RACK, A.; RACK, T.; STILLER, M.; RIESEMEIER, H.; ZABLER, S.; NELSON, K. In vitro synchrotron-based radiography of micro-gap formation at the implant abutment interface of two-piece dental implants. J Synchrotron Radiat, v. 17, n. 2, p. 289-94, 2010.

RICOMINI FILHO, A.P.; FERNANDES, F.S.; STRAIOTO, F.G.; DA SILVA, W.J.; DEL BEL CURY, A.A. Preload loss and bacterial penetration on different implant-abutment connection systems. Braz Dent J, v. 21, n. 2, p. 123-9, 2010.

SANTIAGO, J.F.Jr.; BATISTA, V.E.; VERRI, F.R.; HONÓRIO, H.M.; DE MELLO, C.C.; ALMEIDA, D.A.; PELLIZZER, E.P. Platform-switching implants and bone preservation: a systematic review and meta-analysis. Int J Oral Maxillofac Surg, v. 45, n. 3, p. 33245, 2015

SCHMITT, C.M.; NOGUEIRA FILHO, G.; TENENBAUM, H.C.; LAI, J.Y.; DORING, H.; NONHOFF, J. Performance of conical abutment (morse taper) connection implants: a systematic review. J Biomed Mater Res A, v. 102, n. 2, p. 552-74, 2014.

SHIN, Y.K.; HAN, C.H.; HEO, S.J.; KIM, S.; CHUN, H.J. Radiographic evaluation of marginal bone level around implants with different neck designs after 1 year. Int $\mathbf{J}$ Oral Maxillofac Implants, v. 21, n. 5, p. 789-94, 2016.

STRIETZEL, F.P.; NEUMANN, K.; HERTEL, M. Impact of platform switching on marginal peri-implant bone-level changes. A systematic review and meta-analysis. Clin Oral Implants Res, v. 26, n. 3, p. 342-58, 2015.

SUÁREZ-LÓPEZ DEL AMO, F.; LIN, G.H.; MONJE, A.; GALINDO-MORENO, P.; WANG, H.L. Influence of soft tissue thickness on peri-implant marginal bone loss: a systematic review and meta-analysis. J Periodontol, v. 87, n. 6, p. 690-9, 2016.

TAL, H.; SOLDINGER, M.; DREJANGEL, A.; PITARU, S. Periodontal response to long-term abuse of the gingival attachment by supracrestal amalgam restorations. $\mathbf{J}$ Clin Periodontol, v. 16, n. 10, p. 654-9, 1989.

TUNES, F.S.; COELHO, P.G.; HIRATA, R.; FARDIN, V.P.; ALMEIDA, A. L. P. F.; BONFANTE, E.A. Prótese sobre implante: implicações clínicas do tipo de conexão e forma de fixação. In $\mathbf{5 0}$ anos de osseointegração: reflexões e perspectivas, v. 1, p. 100-11, 2015.

VAN EEKEREN, P.; VAN ELSAS, P.; TAHMASEB, A.; WISMEIJER, D. The influence of initial mucosal thickness on crestal bone change in similar macrogeometrical implants: a prospective randomized clinical trial. Clin Oral Implants Res, v. 28, n. 2, p. 214-218, 2017. 
VERVAEKE, S.; DIERENS, M.; BESSELER, J.; DE BRUYN, H. The influence of initial soft tissue thickness on peri-implant bone remodeling. Clin Implant Dent Relat Res, v. 16, n. 2, p. 238-47, 2014.

VERVAEKE, S.; MATTHYS, C.; NASSAR, R.; CHRISTIAENS, V.; COSYN, J.; DE BRUYN, $\mathrm{H}$. Adapting the vertical position of implants with a conical connection in relation to soft tissue thickness prevents early implant surface exposure: a 2-year prospective intra-subject comparison. J Clin Periodontol, v. 45, n. 5, p. 605-612, 2018.

VIGOLO, P.; GRACIS, S.; CARBONCINI, F.; MUTINELLI, S. AIOP (Italian Academy of Prosthetic Dentistry) CLINICAL RESEARCH GROUP. Internal versus external connection single implants: a retrospective study in an Italian population treated by certified prosthodontists. Int J Oral Maxillofac Implants, v. 31, n. 6, p. 1385-96, 2016.

WAERHAUG, J. Histologic considerations which govern where the margins of restorations should be located in relation to gingiva. Dent Clin North Am, v. 4, n. 2, p. 161-76, 1960.

WENZEL, B.A.; GAMBORENA, I.; LEE, J.; FIORINI, T.; SCHUPBACH, P.; WIKESJO, U.M.; SUSIN, C. Effect of platform shift on crestal bone levels and mucosal profile following flap surgery and subcrestal implant placement in presence/absence of gap defects. Clin Implant Dent Relat Res, v. 18, n. 2, p. 217-25, 2014 